\title{
Medical management of primary open-angle glaucoma: Best practices associated with enhanced patient compliance and persistency
}

\author{
Sadhana V Kulkarni ${ }^{1,2}$ \\ Karim F Damji ${ }^{1,2}$ \\ Yvonne M Buys ${ }^{3}$ \\ 'University of Ottawa Eye Institute, \\ Ottawa, ON, Canada; ${ }^{2}$ Ottawa Health \\ Research Institute, Ottawa, ON, Canada; \\ ${ }^{3}$ Department of Ophthalmology and \\ Vision Sciences, University of Toronto, \\ Toronto, ON, Canada
}

\begin{abstract}
Primary open angle glaucoma is a chronic optic neuropathy often requiring lifelong treatment. Patient compliance, adherence and persistence with therapy play a vital role in improved outcomes by reducing morbidity and the economic consequences that are associated with disease progression. A literature review including searches of The Cochrane Library, MEDLINE, PubMed, conference proceedings, and bibliographies of identified articles reveals the enormous public health burden in various populations due to the impact of glaucoma associated visual impairment on the overall quality of life eg, fear of blindness, inability to work in certain occupations, driving restrictions, motor vehicle accidents, falls, and general health status. Providing specific definitions for the frequently misunderstood terms "compliance, persistence and adherence" with reference to medication use is central not only for monitoring patients' drug dosing histories and clinical outcomes but also for subsequent research. In this review article, a summary of the advantages/disadvantages including cost-effectiveness of various medical approaches to glaucoma treatment, techniques employed for measuring patient compliance and actual patient preferences for therapy are outlined. We conclude by identifying the key barriers to ongoing treatment and suggest some best practices to enhance compliance and persistence.
\end{abstract}

Keywords: glaucoma, compliance, persistence, medication therapy management

Primary open angle glaucoma (POAG) is a chronic, progressive optic neuropathy characterized structurally by optic disc and retinal nerve fiber layer thinning and functionally by defects starting initially in the peripheral vision as measured by a visual field test. Recently, glaucoma has emerged as a leading cause of irreversible vision loss worldwide and is an issue of major public health importance. It is estimated to affect 66 million people worldwide, with at least 6.8 million people bilaterally blind from the condition (Quigley 1996). Individuals of African ancestry have a higher prevalence, earlier age of onset, and often a more aggressive form of POAG vs Caucasian populations (Leske et al 1994; Quigley and Vitale 1997; Friedman et al 2004, 2006). Once diagnosed, it heralds the onset of lifelong therapy, careful monitoring of the optic disc and retinal nerve fiber layer (RNFL) for damage along with periodic visual field checks.

Currently the mainstay of treatment is reduction in intraocular pressure (IOP) enough to achieve a therapeutic goal termed the 'target IOP range' (Damji et al 2003). This is the level of IOP at which further optic nerve and/or visual field damage is not expected to occur. There is now good evidence from randomized controlled trials that lowering IOP to target levels slows optic nerve and/or visual field damage (CNTG 1998; Kass et al 2002; Leske et al 2003; Nemesure et al 2007). IOP also appears to be the only risk factor that can be easily modified and objectively monitored by eye
Correspondence: Sadhana Kulkarni University of Ottawa Eye Institute, 50I Smyth Road, Ottawa,

ON-KIH 8L6, Canada

$\mathrm{Tel}+\mathrm{I} 61332 \mid 8869$

Email skulkarni@ohri.ca 
care professionals such as ophthalmologists and optometrists thereby minimizing conversion rates of ocular hypertension (OHT) to glaucoma and disease progression in established glaucoma (CNTG 1998; Kass et al 2002; Leske et al 2003; Nemesure et al 2007). Besides, appropriate and timely sharing of target IOP with patients and physician colleagues often helps to strengthen therapeutic and collegial relationships.

\section{Treatment decisions and effects on quality of life}

Achieving target IOP range in POAG involves a fine balance between judicious use of medication and other strategies to lower IOP while simultaneously preserving patients' vision and ensuring an acceptable overall quality of life. Treatment is often initiated in a stepwise fashion beginning with topical drug therapy (single then multidrug combinations) followed by laser trabeculoplasty, and if needed, filtering surgery (trabecular meshwork or Schlemm's canal surgery, trabeculectomy, and implantation of shunts) aimed at draining aqueous humor from the eye (AAO 2005; LeBlanc 2007). While caregivers are typically keen on achieving target IOPs, using maximum tolerated medications with least side effect profiles and deciding on the type of surgery the patient should undergo lest medications fail, we find our patients frequently have different goals. In one study, when 82 patients were questioned about their biggest anxiety related to therapy, without doubt most harbored concerns about immediate moderate visual impairment that could impact their freedom and the risk of blindness (Bhargava et al 2006). Translated to the real world situation, their anxiety was about inability to work in certain occupations, restrictions to driving and involvement in motor vehicle accidents (MVA), apprehension of falls and deterioration in general health status, and last but not the least, fear of eventual blindness (Haymes et al 2007). When probed further, other disturbing misconceptions regarding glaucoma therapy were revealed. About half of established glaucoma patients believed that symptoms would warn them of disease progression, about one-third of new patients considered blindness to be a common outcome of glaucoma and most patients thought that topical medications did not have any systemic side-effects (Danesh-Meyer et al 2008). In many ways, it is a gentle reminder that long-term therapy also entails quality of life (QOL) issues. A study that evaluated these QOL issues categorized patients mainly into two groups based on their main priorities as "reading and seeing detail" and "outdoor mobility", the latter changing to the former with increasing visual field loss and an increased willingness to trade time off for therapy thus resulting in a situation of forced compliance (Aspinall et al 2008). Considering this, it is remarkable how, the entire viewpoint of treating glaucoma has gradually changed to preserving "visual function" while ensuring minimal effects on QOL in terms of cost, treatment regime, follow-up schedules as well as socio economic burden (Janz et al 2001; Parikh et al 2008).

\section{Patient education and counseling}

Having said that, the role of a physician as an educator and counselor to bridge the overwhelming gap in knowledge transfer, cannot be over emphasized. It has been shown that educational interventions that specifically target improving levels of health literacy have a positive influence on subjects' adherence to a therapeutic regime in terms of number of refills obtained more than any other factor such as age, ethnicity, gender, and economic status (Muir et al 2006; Juzych et al 2008). These interventions can be highly successful if conducted at regular intervals in a support group setting as a structured program with an opportunity for patients to discuss various concerns related to disease process and treatment (Blondeau et al 2007; Danesh-Meyer et al 2008).

\section{Definitions}

Although it is obvious that successful management of POAG depends heavily on patient compliance with a prescribed treatment plan and that compliance with medications has shown to slow the progression of POAG, numerous research studies have also shown that patient behavior towards compliance and adherence to treatment is far from perfect (Shaw 2005). To this end, studies are designed to investigate and gauge patient noncompliance using various measures like patient self-reports, medication possession ratios, pharmacy refills claims data, medication monitors, etc, (Quigley et al 2007). So when patients state, "I take my eye drops faithfully", how does the practitioner know that they are truly compliant? What is the meaning of the terms "adherence and persistence" that one often reads about in research studies and are they similar to 'compliance'? (Best 2007).

Traditionally, most practitioners have viewed compliance as a more "passive" means of taking medication as opposed to adherence that implies a more "active" process in which the patient assumes an active role in making decisions regarding the treatment algorithm. To this end, an extensive literature search revealed that medication compliance and adherence are actually two different terms (Best 2007; Joyce et al 2008). Medication compliance refers to "the degree or extent of conformity to the recommendations of day-to-day 
treatment by the provider with respect to timing, dosage and frequency." Worded differently it means "the extent to which the patient acts in accordance with the prescribed interval, and dose of a dosing regimen". Hence "compliance" has more to do with the accuracy with which a patient follows the treatment plan as opposed to the extent to which he/she continues the treatment, which is what "adherence" stands for.

Using this definition, we found that reasons for patient noncompliance to eye-drops can indeed be multifactorial, however the major factors that influence patient attitudes are frequency of application (Buller et al 2007; Robin et al 2007), ease of use (Nordstrom et al 2005; Robin et al 2007), comfort (Shibuya et al 2003), tolerability of side effects and perceived benefits (Detry-Morel 2006). For a slowly progressive, nonlife-threatening and asymptomatic disease like POAG, long term compliance is a significant issue (Shaw 2005). Most indexing services like MEDLINE and PubMed, select "compliance" as the primary term and "adherence" as a synonym and use it interchangeably. However, if the above-mentioned definitions were to be used to gauge patient medication use and for reporting related research, then "compliance" might be an appropriate term if viewed in the short term and "adherence" appropriate if viewed over a longer period of time.

Persistence, on the other hand, refers to the act of continuing the treatment for the prescribed duration. It may be defined as "the duration of time from initiation to discontinuation of therapy" (Joyce et al 2008) (Figure 1). Consequently, this can only be measured indirectly from past patient records, returned emptied dropper bottles, prescription refill data, and observation of side effects characteristic to the drug prescribed eg, miotic pupils with pilocarpine or long eyelashes with latanoprost on repeated

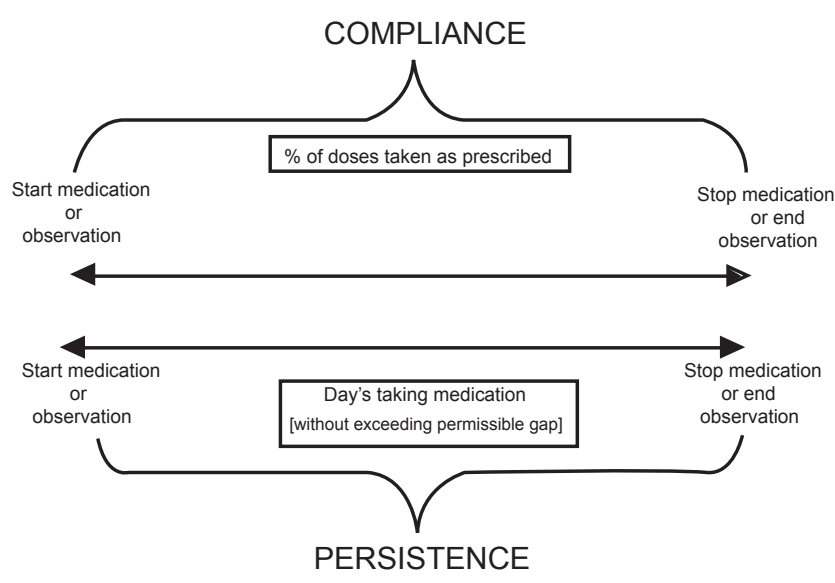

Figure I Definition of compliance and persistence. Copyright $(\subset) 2008$. Adapted with permission from Joyce AC, Ahuja R, Anita B, et al 2008. Medication compliance and persistence: terminology and definitions. Value Health, II:44-7. follow-up appointments (Bour et al 1993). Other ways of measuring patient persistence would be to directly evaluate patients' IOP controlled days as opposed to a single IOP recording; which would definitely be more accurate but very cumbersome to perform (Schwartz and Platt 2002).

Interestingly, the National Health Service in UK prefers to use the term "concordance" to involve the patient in the treatment process so that he/she can participate with the provider in treatment decisions as to which course of action to take, and is thereby partially responsible for monitoring and reporting back to the team.

\section{Choice of medical therapy}

Although medical treatment for glaucoma is improving, there is no single perfect therapy. In our opinion, the characteristics of an ideal IOP-lowering eye drop would include: 1. Proven efficacy in reducing IOP consistently over a 24-hour period to a level sufficient to protect the optic nerve and visual field from further damage; 2 . Have minimal local and systemic adverse effects; 3 . No tachyphylaxis and good tolerance over time; 4. Minimal frequency of dosage in order to promote full patient compliance; and finally, 5. Applicability in diverse patient populations (Obstbaum et al 2004). To many caregivers, this would sound akin to a very demanding yet unrealistic list. To date, prostaglandin analogues (PGAs) closely fulfill these criteria in many situations (ie, sustained efficacy, and safety profile with few systemic side effects. Ocular tolerability is generally good, but issues of conjunctival hyperemia, periorbital and iris pigmentation, eyelash growth, etc, do limit applicability in some patients).

In North America, there is a significant trend towards prescribing PGAs as the first-line monotherapy in newly diagnosed POAG (Mansberger et al 2007). These are the most recently introduced class of glaucoma drugs with superior IOP efficacy, once daily dosing and with very minimal systemic side effects. There can however be considerable though not necessarily unpleasant ocular side effects. One study that reviewed three ophthalmology practices in Alberta, Canada found that compared to other first- and second-line forms of therapy, latanoprost either alone or in combination with beta-blockers was associated with greater reductions in IOP, better therapeutic persistence, fewer therapy switches and lesser visits to the ophthalmologist (Tingey et al 2005). Notwithstanding the above, timolol (Beta-blocker), despite it's contraindications and side-effect profile, is still probably the most used topical glaucoma medication worldwide owing to its availability, lower cost, and long experience 
(Sood et al 1991). In fact, it is one of the first line medications for glaucoma in the developing world.

Despite the good IOP-lowering effect of PGA, some patients may not be well controlled on monotherapy and may require additional medication. This requirement for 2 or more medications is well documented in the major randomized control trials such as the Ocular Hypertension Treatment Study where $49 \%$ of patients required more than one medication and the Collaborative Initial Glaucoma Treatment Study where $75 \%$ required supplementary medication. For the reader interested in the indications and side effects of the most commonly used antiglaucoma drugs, we have included the summary of the various commonly used antiglaucoma medications as an appendix at the end of the article. It is important to note that several medications include a dosing regimen that is two, three or even four times daily, thus limiting utility if patients are unable to remember dosing at certain times of day.

\section{Socioeconomic burden}

When it comes to evaluating the costs associated with long-term therapy, most studies in literature have evaluated the cost of glaucoma medications by assessing the number of drops per bottle and associated cost per drop or per treatment dose (Sood et al 1991; Vicente et al 2004; Rouland et al 2005a; Goldberg and Walt 2006; Schmier et al 2007). A leading study done three years ago that prospectively looked at the expenditure involved in treating glaucoma and OHT over a two-year period in France found that the average daily cost for latanoprost monotherapy was similar to patients who failed beta-blocker monotherapy and that both drugs together did not cost more than therapeutic combinations without latanoprost (Rouland et al 2005b). There are other cost-effectiveness models that compare one of the newer prostaglandin analogues with older medications or with one another. For instance, a newer study done in Canada suggested that for patients in whom timolol is not contraindicated, it would be preferable, from a cost-effectiveness standpoint, to initiate treatment with timolol and reserve the prostaglandin analogues as an alternative treatment or as add-on therapy for patients not achieving a clinical response with timolol. The reasons being, although latanoprost is arguably more effective in its IOP-lowering effects than dorzolamide, brimonidine, or timolol, it is also more expensive (Lachaine et al 2008). However, these studies are at best conflicting in their findings. Their usefulness is limited as they generally evaluate unit medication costs without including differential effectiveness in achieving target IOP or costs associated with rectifying adverse effects of various therapies, and thus they provide only one component of real-world costs for glaucoma. Moreover, there is no universal standard to measure effectiveness outcomes including achieving IOP thresholds, IOP-controlled days (Schwartz and Platt 2002), percent reduction in IOP and quality adjusted life years (QALYs). Therefore it becomes a daunting task to calculate the actual total expenditure in a cohort population and thereby implement policy decisions supporting the use of one agent versus another.

Additionally, in the developing world, the algorithm of treatment may vary depending on factors such as patient affordability and availability for follow-up. A study done by a tertiary care center in India reported that more than $70 \%$ of patients who were on a $3+$ drug regime for about 3 years would prefer lasers and surgery because of the cumbersome schedule and financial burden (Sood et al 1991). Although latanoprost, travaprost, and brimonidine are effective monotherapies for lowering IOP in eyes with early to moderate POAG, in the long term primary filtering surgery may be a more viable option especially if the patient has a visually significant cataract requiring surgery as well. Considering the paucity of resources and competing opportunity costs, it might be best if developing countries with limited resources examined best practices of the western world in a conservative and cost-effective manner (Thomas et al 2004). An example of this is the limited use of antimetabolites as an adjunct for primary filtering surgery in the African subcontinent. Despite this, it has been reported that their blebs seem to perform well for longer periods of time as compared to patients of African descent in North America, as the conjunctiva has not been scarred down by the random use of topical hypotensive agents, besides saving on costs for both antimetabolites and long years of topical therapy (Girma et al 2006). To aid clinical decision-making taking QOL into account, the American Academy of Ophthalmology developed by panel consensus an assessment for evaluation of therapy related to POAG based on available evidence and expert opinion. By extensive polling, specific guidelines were developed to help practitioners in making clinical decisions regarding switching of therapy, use of adjunctive therapy and assessment/ modification of medical therapy with surgery as a primary modality of treatment (Singh et al 2008).

\section{Barriers to compliance and persistence}

There are numerous barriers that prevent patients from accessing complete treatment: psychological, socioeconomic, poor health literacy, inadequate information and inadequate patient-provider relationships. Many studies have reported multiple obstacles to 
adherence in the form of poor education, lack of motivation, forgetfulness, drop application, and other practical issues, together with specific individual and age differences. In fact one study classified the barriers into a four category system and commented that patient compliance was affected by $49 \%$ due to social/environmental factors (lack of support, major life events and travel), $32 \%$ by regimen factors (complexity, costs and change in medication), $16 \%$ by individual patient factors (knowledge, memory, motivation) and 3\% by medical provider factors (dissatisfaction, communication) (Table 1, Figure 2). For many patients the source of motivation for adherence is determined by fear of blindness coupled with a faith in drop efficacy (Tsai et al 2003; Lacey et al 2008).

A recently completed multicenter study across major cities in Canada assessed the reasons for noncompliance in a questionnaire-based survey. Forgetfulness followed by travel was cited as the most common reason for defaulting on eye drop use (Kholdebarin et al 2008) (Figure 3).

\section{Key strategies to enhance compliance and persistence}

A number of simple yet effective changes can be implemented to overcome some of these barriers. For instance patients showed improvement in accuracy of reporting medications and hence compliance when given written instructions about their regimen, regardless of their level of education or number of medications (Jampel et al 2005; Kharod et al 2006). Providing patients with an easy medication scheduler and reminder in the form of a handout can go long ways to encourage the patient to use the correct eye drops at the appropriate time (Figure 4). Similarly, in a highly motivated patient, maintenance of a medication diary can help the health care provider track persistence over time (Jampel et al 2005; Kharod et al 2006).

The use of medication monitors, alarm clocks and Travalert $^{\circledR}$ devices has been advocated for patients who need reminders for therapy when traveling (NIH 2008). For some patients in whom manual dexterity might be compromised the use of an eye guide may aid in accurate instillation of the eye drops without wastage or contamination but it might actually be counter productive in others (Salyani and Birt 2005). And although there is no straightforward linear relationship between complexity of eye drop regime and compliance, in some patients, particularly those with memory problems such as Alzheimer's disease prescribing fewer drops may mean better compliance (Buller et al 2007).

Table I Taxonomy of barriers to adherence

\begin{tabular}{|c|c|}
\hline Categories & Sample statement \\
\hline \multicolumn{2}{|l|}{ I. Region factors } \\
\hline Refill & I only forget to take my drops when I run out. \\
\hline Cost of medication & When my insurance stopped paying for my medication I didn't take my drops. \\
\hline Complexity & It was harder when I was taking four medications, now that I am taking three it is better. \\
\hline Change & When I first started taking the drops I had a harder time remembering. \\
\hline Side effects & I decided to quit taking my drops because I had a bad reaction from them. \\
\hline \multicolumn{2}{|l|}{ 2. Patient factors } \\
\hline Knowledge/skill & Sometimes I miss my eye when taking my drops. \\
\hline Memory & Sometimes I just forget to take my drops. \\
\hline Motivation/health beliefs & I quit taking my drops because I didn't see benefit to them and didn't think they were working. \\
\hline Co-morbidity & It is harder to keep track of my drops because I am taking so many other medications. \\
\hline \multicolumn{2}{|l|}{ 3. Provider factors } \\
\hline Dissatisfaction & I quit taking my drops because I was dissatisfied with my doctor's care. \\
\hline Communication & I stopped taking my drops because I didn't understand initially that I need to take them forever. \\
\hline \multicolumn{2}{|l|}{ 4. Situational/environmental factors } \\
\hline Accountability/lack of support & Living alone I had problems taking my drops; now I live with my daughter and have no problems. \\
\hline Major life events & Two years ago when my wife died I had a hard time taking my drops. \\
\hline Travel/away from home & When I am on vacation it is more difficult to take my drops. \\
\hline Competing activities & I miss my drops on Sunday mornings when I go to church. \\
\hline Change in routine & $\begin{array}{l}\text { Lifestyle changes that occur on the weekends, such as not getting up at a normal hour, cause me } \\
\text { to forget to take my drops. }\end{array}$ \\
\hline
\end{tabular}

Note: Copyright $\odot$ 2003, Lippincott Williams and Wilkins. Reproduced with permission from Tsai JC, McClure CA, Ramos SE, et al 2003. Compliance barriers in glaucoma: a systematic classification.J Glaucoma, 12:393-8. 


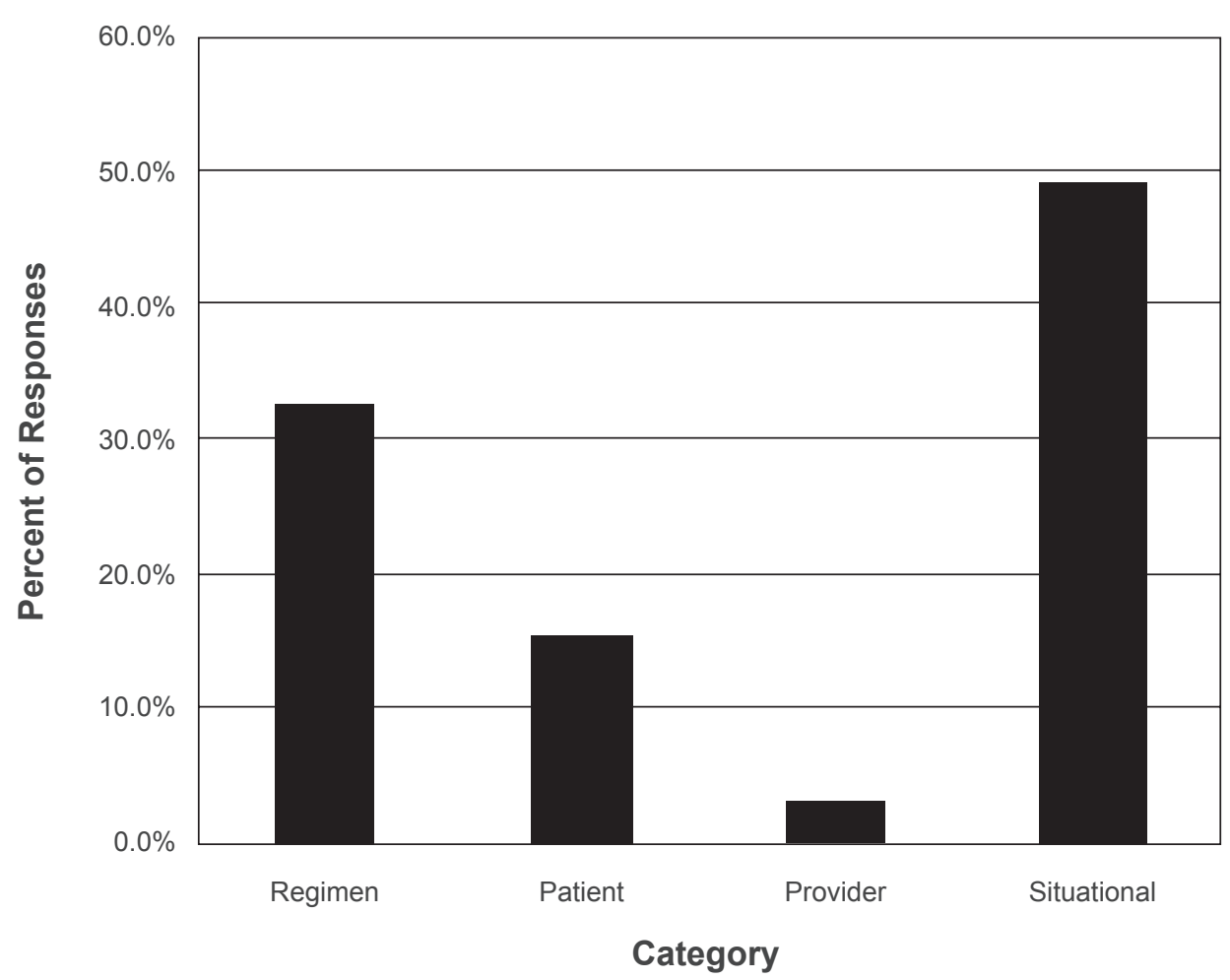

Figure 2 Percentage distributions of adherence barriers. Copyright @ 2003, Lippincott Williams and Wilkins. Reproduced with permission from Tsai JC, McClure CA, Ramos SE, et al 2003. Compliance barriers in glaucoma: a systematic classification.J Glaucoma, 12:393-8.

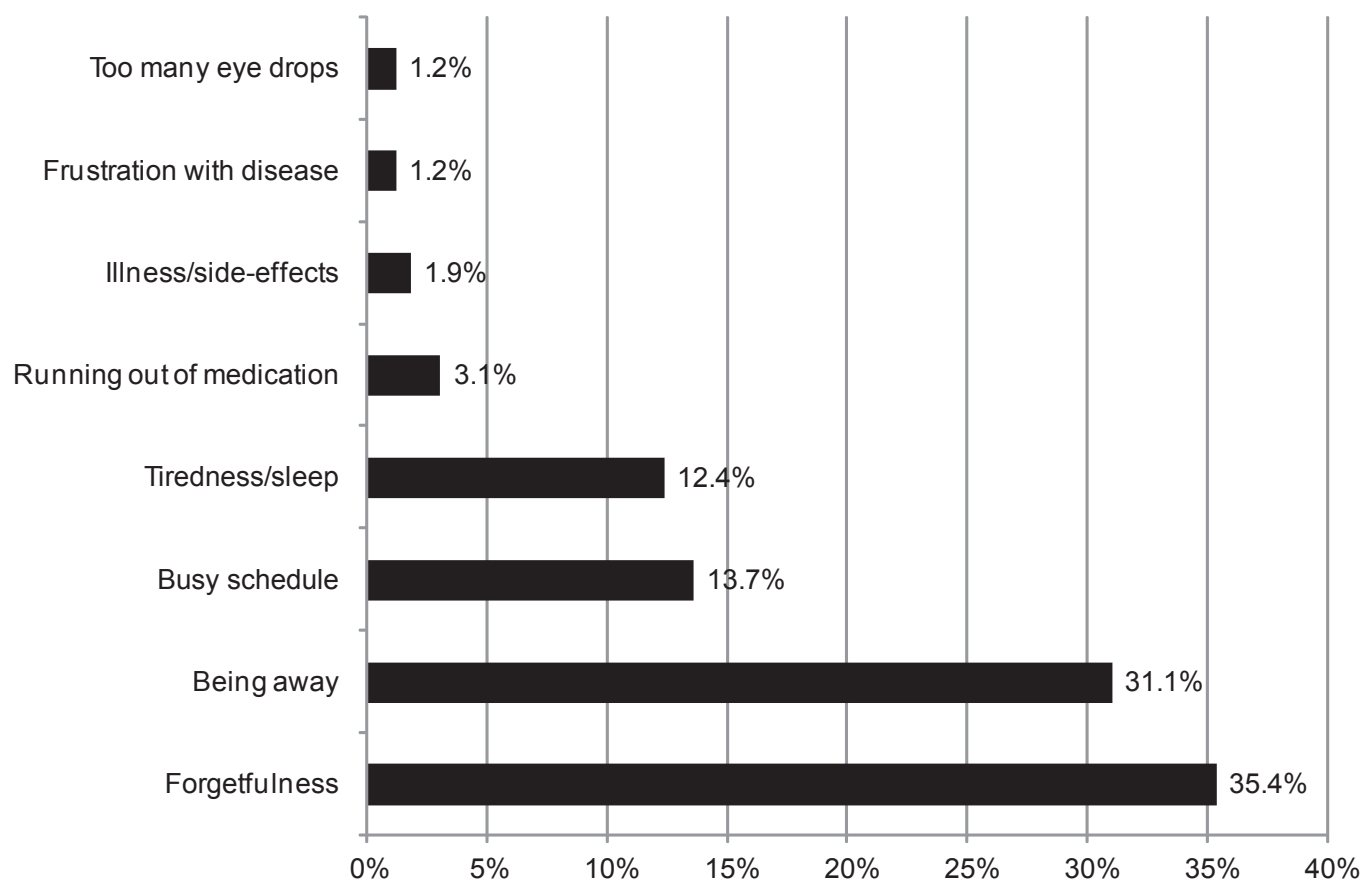

Percentage of patients who reported a reason for noncompliance

Figure 3 Reasons given by glaucoma patients for missing eye drop medication. Copyright $\odot$ 2008. Reproduced with permission from Kholdebarin R, Jin Y, Campbell RJ, et al 2008. Multicenter study of compliance and drop administration in glaucoma. Can J Ophthalmol, 43:454-61. 

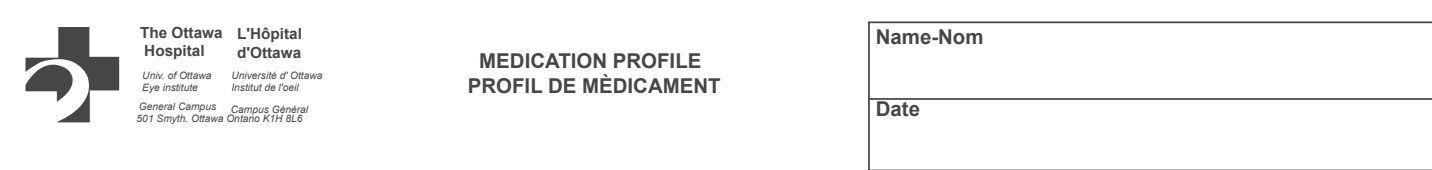

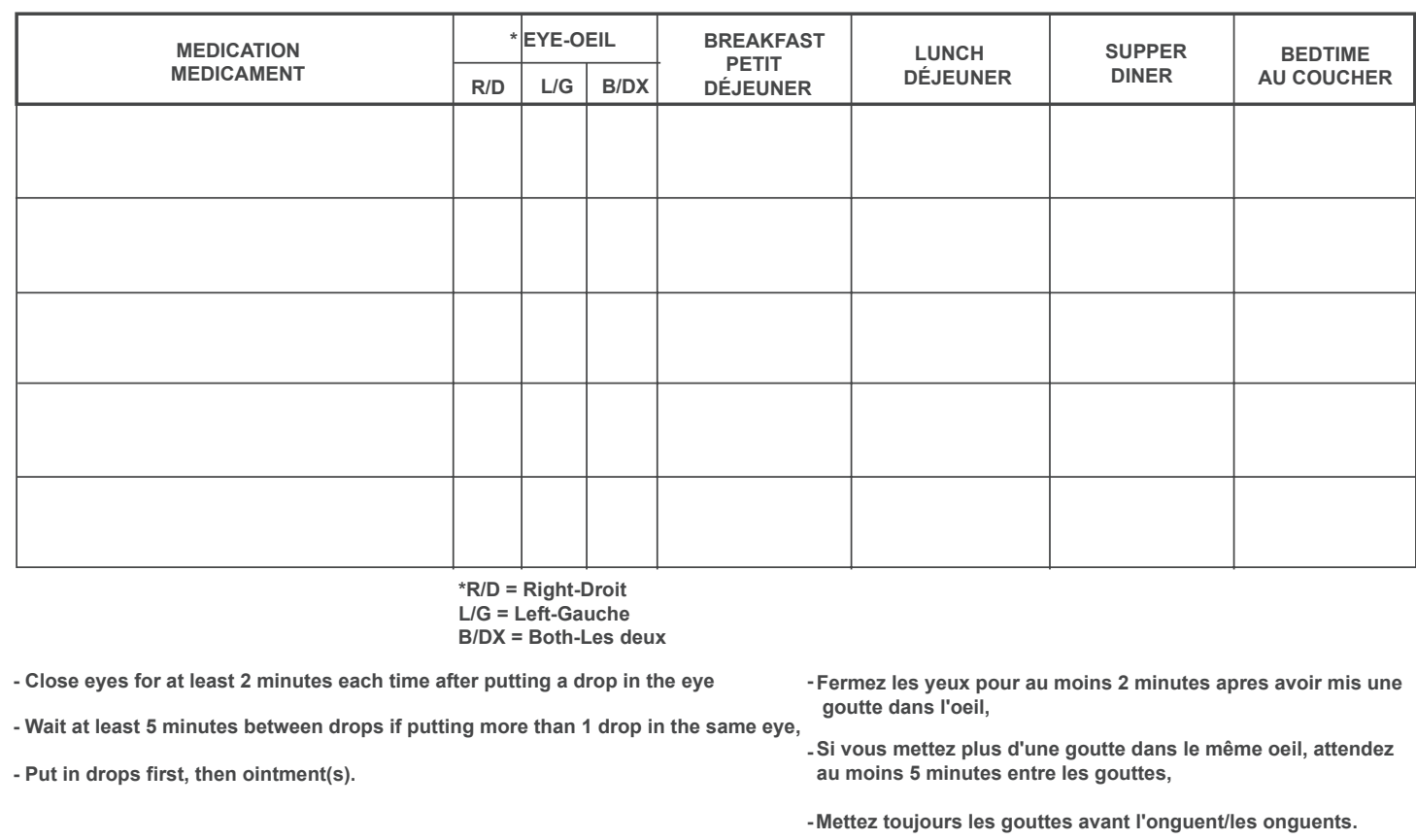

EYE 15 EF (02/99)

Figure 4 Medication scheduler and reminder sheet (Courtesy University of Ottawa Eye Institute, Ottawa, Canada).

As a rule, it has been found that compliance is enhanced when patients self-medicate. However, if there is a possibility that physical or mental disability might hamper the prospects of self-medication, then involvement of a committed family member or friend in the actual drop instillation process becomes a necessity. Other drivers of patient adherence to topical ocular hypotensive therapy include a healthy communication with professional caregivers, participating in appropriate educational interventions to get information regarding the anticipated natural history with and without treatment and progression of the disease and its consequences, understanding the risks and benefits of treatment in preserving vision-related QOL, and being able to make an informed choice as to available management options (Blondeau et al 2007; Friedman et al 2008).

\section{Conclusion}

This article reviews the various medical approaches to care of patients with POAG. There is an overview of various methods to measure medication compliance and an estimation of the problems related to noncompliance. Emphasis has been laid on the importance of focusing treatment around optimizing patient-related QOL. Lowering IOP to target levels and ensuring compliance and persistency with medical therapy in POAG is fundamental to preventing or slowing glaucomatous visual loss. Similarly, simplification of the treatment regimen, selection of medications with the fewest systemic and ocular side effects, and improving patient-physician relationship can have a significant impact on preventing deterioration due to noncompliance. However, as there are many barriers to effective treatment; it is important to understand these as well as best practices to enhance compliance and persistency in a manner that keeps in mind optimal utilization of finite human and financial resources for the patient, practitioner, and health care system. Some tips to achieve the aforementioned include:

1. Optimal utilization of evidence-based clinical guidelines for therapy in POAG.

2. Keep treatment plan straightforward and tailored to patient needs/preferences.

3. Recognize early in the treatment plan the possible obstacles to compliance and persistence and plan interventions accordingly (eg, low health literacy which can be addressed by patient education sessions). 
4. Monitor progression of disease, quality of life, and institute timely additional intervention(s) as required (Grol and Grimshaw 1999).

\section{Acknowledgments}

The authors would like to thank Dr Daniel Kiage for help with compiling the medication table and Amy Bovell for support with proof reading.

\section{References}

[AAO] American Academy of Ophthalmology. 2005. Preferred Practice Pattern: Primary Open Angle Glaucoma. San Francisco, CA. American Academy of Ophthalmology.

[CNTG] Collaborative Normal-Tension Glaucoma Study Group. 1998. The effectiveness of intraocular pressure reduction in the treatment of normal-tension glaucoma. Collaborative Normal-Tension Glaucoma Study Group. Am J Ophthalmol, 126:498-505.

Aspinall PA, Johnson ZK, Azuara-Blanco A, et al. 2008. Evaluation of quality of life and priorities of patients with glaucoma. Invest Ophthalmol Vis Sci, 49:1907-15.

Best SJ. 2007. Does persistency truly equate to compliance? Clin Exper Ophthalmol, 35:593.

Bhargava JS, Patel B, Foss AJ, et al. 2006. Views of glaucoma patients on aspects of their treatment: an assessment of patient preference by conjoint analysis. Invest Ophthalmol Vis Sci, 47:2885-8.

Blondeau P, Esper P, Mazerolle E. 2007. An information session for glaucoma patients. Can J Ophthalmol, 42:816-20.

Bour T, Blanchard F, Segal A. 1993. [Therapeutic observance and life of patients with primary open-angle glaucoma. Apropos of 341 cases in the department of Marne.]. J Fr Ophtalmol, 16(6-7):380-91.

Buller AJ, Morgan LH, Hercules BL. 2007. Patients prefer once-daily glaucoma drops. Graefes Arch Clin Exper Ophthalmol, 245:293-4.

Damji KF, Behki R, Wang L; Target IOP Workshop. 2003. Canadian perspectives in glaucoma management: setting target intraocular pressure range. Can J Ophthalmol, 38:189-97.

Danesh-Meyer HV, Deva NC, Slight C, et al. 2008. What do people with glaucoma know about their condition? A comparative cross-sectional incidence and prevalence survey. Clin Exper Ophthalmol, 36:13-8.

Detry-Morel M. 2006. [Compliance and persistence.]. J Fr Ophtalmol, 29:216-25.

Friedman DS, Hahn SR, Gelb L, et al. 2008. Doctor-patient communication, health-related beliefs, and adherence in glaucoma results from the Glaucoma Adherence and Persistency Study. Ophthalmology, 115:1320-7.

Friedman DS, Jampel HD, Munoz B, et al. 2006. The prevalence of open-angle glaucoma among blacks and whites 73 years and older: the Salisbury Eye Evaluation Glaucoma Study. Arch Ophthalmol, 124:1625-30.

Friedman DS, Wolfs RC, O'Colmain BJ, et al, Eye Diseases Prevalence Research Group. 2004. Prevalence of open-angle glaucoma among adults in the United States. Arch Ophthalmol, 122:532-8.

Girma T, Courtright P, Mengistu F, et al. 2006. A placebo controlled double blind clinical trial of mitomycin $\mathrm{C}$ in primary trabeculectomy in Ethiopian patients. Ethiop Med J, 44:253-6.

Goldberg LD, Walt J. 2006. Cost considerations in the medical management of glaucoma in the US: estimated yearly costs and cost effectiveness of bimatoprost compared with other medications. Pharmacoeconomics, 24:251-64.

Grol R, Grimshaw J. 1999. Evidence-based implementation of evidence-based medicine. Jt Comm J Qual Improv, 25:503-13.

Haymes SA, LeBlanc RP, Nicolela MT, et al. 2007. Risk of falls and motor vehicle collisions in glaucoma. Invest Ophthalmol Vis Sci, 48:1149-55.
Jampel HD, Parekh P, Johnson E, et al. 2005. Chart documentation by general physicians of the glaucoma medications taken by their patients. Am J Ophthalmol, 140:344-5.

Janz NK, Wren PA, Lichter PR, et al; CIGTS Study Group. 2001. The Collaborative Initial Glaucoma Treatment Study: interim quality of life findings after initial medical or surgical treatment of glaucoma. Ophthalmology, 108:1954-65.

Joyce AC, Ahuja R, Anita B, et al. 2008. Medication compliance and persistence: terminology and definitions. Value Health, 11:44-7.

Juzych MS, Randhawa S, Shukairy A, et al. 2008. Functional health literacy in patients with glaucoma in urban settings. Arch Ophthalmol, 126:718-24.

Kass MA, Heuer DK, Higginbotham EJ, et al. 2002. The Ocular Hypertension Treatment Study: a randomized trial determines that topical ocular hypotensive medication delays or prevents the onset of primary open-angle glaucoma. Arch Ophthalmol, 120:701-13.

Kharod BV, Johnson PB, Nesti HA, et al. 2006. Effect of written instructions on accuracy of self-reporting medication regimen in glaucoma patients. J Glaucoma, 15:244-7.

Kholdebarin R, Jin Y, Campbell RJ, et al. 2008. Multicenter study of compliance and drop administration in glaucoma. Can J Ophthalmol, 43:454-61.

Lacey J, Cate H, Broadway DC. 2008. Barriers to adherence with glaucoma medications: a qualitative research study. Eye, Apr 25. [Epub ahead of print]

Lachaine J, Hodge WG, Steffensen I, et al. 2008. Prostaglandin analogues for ophthalmic use: a cost-effectiveness analysis. Can J Ophthalmol, 43:33-41.

LeBlanc RP, Canadian Glaucoma Strategy Forum. 2007. A Canadian glaucoma strategy. Can J Ophthalmol, 42:60-5.

Leske MC, Connell AM, Schachat AP, et al. 1994. The Barbados Eye Study. Prevalence of open angle glaucoma. Arch Ophthalmol, 112:821-9.

Leske MC, Heijl A, Hussein M, et al, Early Manifest Glaucoma Trial Group. 2003. Factors for glaucoma progression and the effect of treatment: the early manifest glaucoma trial. Arch Ophthalmol, 121:48-56.

Mansberger SL, Hughes BA, Gordon MO, et al; Ocular Hypertension Treatment Study Group. 2007. Comparison of initial intraocular pressure response with topical beta-adrenergic antagonists and prostaglandin analogues in African American and white individuals in the Ocular Hypertension Treatment Study. Arch Ophthalmol, 125:454-9.

Muir KW, Santiago-Turla C, Stinnett SS, et al. 2006. Health literacy and adherence to glaucoma therapy. Am J Ophthalmol, 142:223-6.

Nemesure B, Honkanen R, Hennis A, et al; Barbados Eye Studies Group. 2007. Incident open-angle glaucoma and intraocular pressure. Ophthalmology, 114:1810-15.

[NIH] US National Institutes of Health. 2008. Clinical Trials Search [online]. Accessed on Sept 29, 2008. URL: http://clinicaltrials.gov/ show/NCT00508469.

Nordstrom BL, Friedman DS, Mozaffari E, et al. 2005. Persistence and adherence with topical glaucoma therapy. Am J Ophthalmol, 140:598-606.

Obstbaum SA, Cioffi GA, Krieglstein GK, et al. 2004. Gold standard medical therapy for glaucoma: defining the criteria identifying measures for an evidence-based analysis. Clin Ther, 26:2102-20.

Parikh RS, Parikh SR, Navin S, et al. 2008. Practical approach to medical management of glaucoma. Indian J Ophthalmol, 56:223-30.

Quigley HA. 1996. Number of people with glaucoma worldwide. $\mathrm{Br} J$ Ophthalmol, 80:389-93.

Quigley HA, Friedman DS, Hahn SR. 2007. Evaluation of practice patterns for the care of open-angle glaucoma compared with claims data: the Glaucoma Adherence and Persistency Study. Ophthalmology, 114:1599-606.

Quigley HA, Vitale S. 1997. Models of open-angle glaucoma prevalence and incidence in the United States. Invest Ophthalmol Vis Sci, 38:83-91.

Robin AL, Novack GD, Covert DW, et al. 2007. Adherence in glaucoma: objective measurements of once-daily and adjunctive medication use. Am J Ophthalmol, 144:533-40. 
Rouland JF, Berdeaux G, Lafuma A. 2005a. The economic burden of glaucoma and ocular hypertension: implications for patient management: a review. Drugs Aging, 22:315-21.

Rouland JF, Le Pen C, Benhaddi H, et al; Glaucoma Study Group. 2005b. Naturalistic, prospective study of glaucoma and ocular hypertension treatment in France: Strategies, clinical outcomes, and costs at 2 years. Eur J Ophthalmol, 15:562-80.

Salyani A, Birt C. 2005. Evaluation of an eye drop guide to aid self-administration by patients experienced with topical use of glaucoma medication. Can J Ophthalmol, 40:170-4.

Schmier JK, Halpern MT, Jones ML. 2007. The economic implications of glaucoma: a literature review. Pharmacoeconomics, 25:287-308.

Schwartz GF, Platt R. 2002. Measuring persistency and intraocular pressure-controlled days in patients receiving topical glaucoma medications. Am J Manage Care, 8(10 Suppl):S278-80.

Shaw ME. 2005. Increasing compliance with glaucoma therapy: "so, convince me I have something wrong with my eyes". Insight, 30:7-9.

Shibuya T, Kashiwagi K, Tsukahara S. 2003. Comparison of efficacy and tolerability between two gel-forming timolol maleate ophthalmic solutions in patients with glaucoma or ocular hypertension. Ophthalmologica, 217:31-8.
Singh K, Lee BL, Wilson MR, Glaucoma Modified RAND-Like Methodology Group. 2008. A panel assessment of glaucoma management: modification of existing RAND-like methodology for consensus in ophthalmology. Part II: Results and interpretation. Am J Ophthalmol, 145:575-81.

Sood NN, Kumar H, Patil ND, et al. 1991. Medical and socio-economic aspects of long term therapy of open angle glaucoma. Indian $J$ Ophthalmol, 39:91-3.

Thomas R, Sekhar GC, Kumar RS. 2004. Glaucoma management in developing countries: medical, laser, and surgical options for glaucoma management in countries with limited resources. Curr Opin Ophthalmol, 15:127-31.

Tingey D, Bernard LM, Grima DT, et al. 2005. Intraocular pressure control and persistence on treatment in glaucoma and ocular hypertension. Can J Ophthalmol, 40:161-9.

Tsai JC, McClure CA, Ramos SE, et al. 2003. Compliance barriers in glaucoma: a systematic classification. J Glaucoma, 12:393-8.

Vicente C, Walker J, Buys Y, et al. 2004. Association between mean intraocular pressure, disease stability and cost of treating glaucoma in Canada. Curr Med Res Opin, 20:1245-51. 


\section{Appendix I}

\section{Summary of glaucoma medications}

I Adrenergic agonists

\begin{tabular}{|c|c|c|c|c|}
\hline Generic & Trade name & $\begin{array}{l}\text { Mechanism of action } \\
\text { and indications }\end{array}$ & Properties & $\begin{array}{l}\text { Major side effects and } \\
\text { precautions }\end{array}$ \\
\hline Apraclonidine $0.5 \%-1.0 \%$ & lopidine & $\begin{array}{l}\downarrow \text { Aqueous production } \\
\text { Prevents severe elevation } \\
\text { of IOP following laser } \\
\text { procedures }\end{array}$ & $\begin{array}{l}\text {-Max effect in } 4 \text { to } 5 \text { hrs. } \\
\text {-Duration of effect: } 12 \text { hrs. } \\
-\downarrow \text { IOP by } 25 \%-39 \%\end{array}$ & $\begin{array}{l}\text { Cl: in children } \\
\text { Side effects: Dry mouth, lid } \\
\text { elevation, allergy [more with } \\
\text { Apraclonidine] sleepiness, fatigue } \\
\text { headaches, Hypotension } \\
\text { Cl: in patients with monoamine } \\
\text { oxidase inhibitors) }\end{array}$ \\
\hline Brimonidine $0.2 \%$ & $\begin{array}{l}\text { Alphagan } \\
\text { Alphagan } \mathrm{P}(0.15 \% \text { using } \\
\text { Purite as preservative })\end{array}$ & $\begin{array}{l}\downarrow \text { Aqueous production } \\
\uparrow \text { Uveal scleral outflow } \\
\text { Elevation of IOP where } \\
\text { IOP can be deleterious } \\
\text { to visual function }\end{array}$ & $\begin{array}{l}\text { Duration of effect: } 8-12 \mathrm{hr} \\
\text { TID if monotherapy and BID } \\
\text { if adjunctive. } \downarrow \text { IOP by } 27 \%\end{array}$ & \\
\hline
\end{tabular}

2 Beta adrenergic blockers

\begin{tabular}{|c|c|c|c|c|}
\hline Generic & Trade name & $\begin{array}{l}\text { Mechanism of action } \\
\text { and indications }\end{array}$ & Properties & Major side effects and precautions \\
\hline $\begin{array}{l}\text { Betoxolol } 0.25 \%-0.5 \% \\
\text { (selective Beta-I) }\end{array}$ & Betoptic & $\begin{array}{l}\downarrow \text { Aqueous production } \\
\text { Peak effect: } 2 \text { hrs }\end{array}$ & $\begin{array}{l}\text { Better tolerated } \\
\text { than nonselective } \\
\text { but not as effective }\end{array}$ & $\begin{array}{l}\text { Relative } \mathrm{SE} \text { and } \mathrm{Cl} \text { as nonselective } \\
\text { (See below) }\end{array}$ \\
\hline $\begin{array}{l}\text { Timolol } 0.1 \%-0.5 \% \\
\text { [nonselective] }\end{array}$ & $\begin{array}{l}\text { Timoptic } \\
\text { Timoptol } \\
\text { Cusimol }\end{array}$ & Washout: 2-5 wks & $\begin{array}{l}\text { Additive effects to } \\
\text { most IOP-lowering } \\
\text { agents }\end{array}$ & SE: Bradycardia \\
\hline $\begin{array}{l}\text { Levobunolol } 0.25 \%-0.5 \% \\
\text { [nonselective] }\end{array}$ & Betagan & & $\begin{array}{l}\text { Reduces IOP more } \\
\text { than selective }\end{array}$ & $\begin{array}{l}\text { Arrhythmias, heart failure, bronchospasms, } \\
\text { airway obstruction, depression, masks } \\
\text { hypoglycemia in IDDM } \\
\mathrm{CI} \text { - Asthma, obstructive pulmonary } \\
\text { disease, sinus bradycardia, heart block }\end{array}$ \\
\hline
\end{tabular}

3 Carbonic anhydrase inhibitors

Systemic

\begin{tabular}{|c|c|c|c|c|}
\hline Generic & Trade name & Mechanism of action & Properties & Major side effects and precautions \\
\hline \multirow[t]{4}{*}{ Acetazolamide } & $\begin{array}{l}\text { Diamox } \\
\text { Diamox sequel } \\
\text { Diamox retard }\end{array}$ & $\downarrow$ Aqueous formation & Wash-out: 3 days & $\begin{array}{l}\text { Major SE: Parasthesia, GIT symptoms, } \\
\text { depression, } \downarrow \text { libido, kidney stones, blood } \\
\text { dyscrasias, metabolic acidosis, and electrolyte } \\
\text { imbalance }\end{array}$ \\
\hline & & $\begin{array}{l}\text { Indicated when topical } \\
\text { medication is not effective } \\
\text { or feasible }\end{array}$ & May lead to hypokalemia & $\begin{array}{l}\mathrm{Cl} \text { : When sodium and potassium blood levels } \\
\text { are depressed, in kidney and liver disease }\end{array}$ \\
\hline & & & $\begin{array}{l}\text { Dose I } 25-250 \mathrm{mg} \text { QID } \\
\text { or } 500 \mathrm{mg} \text { BD for slow } \\
\text { release }\end{array}$ & In sickle cell anemia \\
\hline & & & & $\begin{array}{l}\text { Precautions: Allergy to sulphonamides } \\
\text { Pregnancy and nursing mothers: Teratogenic } \\
\text { effects reported }\end{array}$ \\
\hline
\end{tabular}


Topical:

\begin{tabular}{lllll}
\hline Generic & Trade name & $\begin{array}{l}\text { Mechanism of action } \\
\text { and indications }\end{array}$ & Properties & Major side effects and precautions \\
\hline Brinzolamide & Azopt & $\mathrm{CAl}-\downarrow$ Aqueous formation. & As monotherapy - TID & $\begin{array}{l}\text { Major SE: Ocular burning and discomfort, } \\
\text { other SE of sulfonamides }\end{array}$ \\
Dorzolamide & Trusopt & $\begin{array}{l}\text { Indicated in elevation of IOP } \\
\text { where IOP can be deleterious } \\
\text { to visual function }\end{array}$ & $\begin{array}{l}\text { As adjunctive to topical } \\
\text { beta blockers - BID } \\
\text { Wash-out: I wk }\end{array}$ & $\begin{array}{l}\text { Precaution: May increase cornea edema } \\
\text { in low endothelial cell count and/or } \\
\text { corneal endothelia dysfunction } \\
\text { (eg, Fuchs' dystrophy) }\end{array}$ \\
& & & Oral and systemic CAI not recommended \\
\hline
\end{tabular}

4 Parasympathomimetics [Cholinergic drugs]

\begin{tabular}{|c|c|c|c|c|}
\hline Generic & Trade name & $\begin{array}{l}\text { Mechanism of action } \\
\text { and indications }\end{array}$ & Properties & Major side effects and precautions \\
\hline Pilocarpine 0.5 to $4 \%$ & $\begin{array}{l}\text { Isoptocarpine, } \\
\text { pilocarpine, } \\
\text { pilogel }\end{array}$ & $\begin{array}{l}\text { Increases facility of out- } \\
\text { flow of aqueous direct } \\
\text { action on longitudinal } \\
\text { ciliary muscles }\end{array}$ & $\begin{array}{l}\text { Pilo lowers IOP in I hr } \\
\text { and lasts 6-7 hrs. Therefore } \\
\text { used QID }\end{array}$ & $\begin{array}{l}\text { Major SE: Intestinal cramps, brochospasms, } \\
\text { miosis, pseudomyopia [upto 8D], brow ache, } \\
\text { retinal detachment, ciliary spasms, increases } \\
\text { pupillary block (dose dependent). }\end{array}$ \\
\hline Carbachol & Isoptocarbachol & $\begin{array}{l}\text { Indicated in elevation } \\
\text { of IOP where IOP can } \\
\text { be deleterious to visual } \\
\text { function }\end{array}$ & Gel used QHS & $\begin{array}{l}\text { Major Cl: Age }<40 \text { yrs, cataract, } \\
\text { uveitis, NVG }\end{array}$ \\
\hline Acetylcholine I\% & $\begin{array}{l}\text { Miochol - for } \\
\text { intracameral use } \\
\text { during surgery }\end{array}$ & & $\begin{array}{l}\text { Miochol used intracameral } \\
\text { during surgery } \\
\text { Drug interaction: } \\
\text { In theory, competitive } \\
\text { interaction on uveoscleral } \\
\text { outflow with prostaglandins } \\
\text { In practice usually not a } \\
\text { problem } \\
\text { Wash out: } 3 \text { days }\end{array}$ & $\begin{array}{l}\text { Precautions: Axial myopia, Hx of RD } \\
\text { or Rhegm. Retinal lesion }\end{array}$ \\
\hline
\end{tabular}

5 Prostaglandin derivatives

\begin{tabular}{|c|c|c|c|c|}
\hline Generic & Trade name & $\begin{array}{l}\text { Mechanism of action } \\
\text { and indications }\end{array}$ & Properties & Major side effects and precautions \\
\hline Bimatoprost $0.03 \%$ & Lumigan & $\uparrow$ Uveal scleral outflow & $\begin{array}{l}\text { IOP-lowering starts } 2-4 \mathrm{hrs} \\
\text { after adm. with peak effect } \\
\text { reached within } 8-12 \mathrm{hrs} \text {. } \\
\text { Max. IOP-lowering often } \\
\text { takes 3-5 wks from start } \\
\text { of treatment }\end{array}$ & $\begin{array}{l}\text { Major SE: *Conjunctival hyperemia. } \\
\text { bimatoprost- } 44.7 \% \text {, latanoprost- } 27.6 \% \text {, } \\
\text { travoprost- } 49.5 \%\end{array}$ \\
\hline Latanoprost $0.005 \%$ & Xalatan & $\begin{array}{l}\text { Bimatoprost may also } \\
\text { increase trabecular } \\
\text { outflow }\end{array}$ & $\begin{array}{l}\text { Once daily dose. Preferably } \\
\text { evening } \\
\text { Washout can take } 4-6 \text { wks }\end{array}$ & $\begin{array}{l}\text { *Burning, stinging, FB sensation, eyelash change } \\
\text { [length, thickness, color] reversible after cessation }\end{array}$ \\
\hline Travoprost $0.004 \%$ & Travatan & & & $\begin{array}{l}\text { *CME in aphakia and pseudophakia - Co-current } \\
\text { use of NSAID may reduce this } \\
\text { *Reactivation of herpes keratitis } \\
\text { *Anterior uveitis } \\
\text { Precautions: Must not administer these drugs } \\
\text { while wearing contact lenses (CLs). But the CLs } \\
\text { can be reinserted } 15 \text { mins following administration }\end{array}$ \\
\hline
\end{tabular}

Notes: Several of the above medications are also available as various fixed drug combinations (typically a beta blocker paired with a prostaglandin analogue, carbonic anhydrase inhibitor or alpha-2 agonist). In general, the adverse effects of these combinations are related to the individual drug components. *Applies to all generic drugs under prostaglandin derivatives.

Abbreviation: $\mathrm{Cl}$, contraindications; $\mathrm{SE}$, side effects; $\mathrm{CAI}$, carbonic anhydrase inhibitors. 
